\title{
Impact Assessment of Eastern Route of South-to-North Water Diversion Project Operation on Water Environmental of Dongping Lake
}

\author{
BAO Yunxiang ${ }^{1, a^{*}}$ \\ ${ }^{1}$ Business School of Hohai University, Nanjing, China
}

\begin{abstract}
The Eastern Route of the South-to-North Water Diversion Project is a national strategic measure to improve the water supply conditions of the cities along the route, Jiaodong and Huaibei regions. However, the Water Diversion Project not only brings social and economic benefits, but also changes the hydrological situation and ecological environment of water source area, transfer area and receiving area. In this paper, Dongping Lake is selected as the research object. By using the analytic hierarchy process and fuzzy evaluation method, the index system of the impact assessment of the Eastern route project on the water environment of Dongping Lake is constructed, and a multi-level fuzzy evaluation model is established to conduct quantitative and qualitative research on the impacts of hydrology, meteorology, water ecological environment, soil and other aspects as well as ecological and economic compensation. The analysis results show that the operation of the Eastern route project has brought some negative effects on Dongping Lake, mainly reflected in the aspects of soil, ecological compensation, hydrology and meteorology, and the negative effects on the water ecological environment are light. By studying the impact of the Eastern route project on the water environment of Dongping Lake, this paper aims to improve the environmental impact assessment system for the water receiving area of the Eastern Route of the South-to-North Water Diversion Project, and to provide reference for the research on the environmental impact assessment system for other water diversion projects in China.
\end{abstract}

\section{Introduction}

The concept of environmental impact assessment (EIA) was first put forward at an international academic conference on environmental quality assessment held in Canada in 1964. After nearly 30 years of development, more than 100 countries have established EIA system successively ${ }^{[1]}$. Governments of various countries attach great importance to the ecological protection of crossbasin water diversion projects, and have formulated a series of laws and policies through exploration and research ${ }^{[2]}$. In 1973, China introduced the concept of environmental impact assessment, and established it in the form of law through the Environmental Protection Law (Trial Implementation) in 1979. Since then, environmental impact assessment system, as one of the "eight systems" of environmental management, has played an important role in many fields.

Taking the Eastern route of the South-to-North Water Diversion Project as an example, the environmental impact studies on the eastern route in China are mainly focused on the Nansi Lake and the Beijing-Hangzhou Grand Canal. For example, Guo Hua et al. (2013) [3] studied the influence of the Eastern route of South-toNorth Water Diversion Project on the water environment of Nansi Lake, and the research results showed that the Eastern route project would have a certain positive impact on the water ecological environment of Nansi Lake. Luo Hui et al. (2005) ${ }^{[4]}$ studied the water environment quality of Nansi Lake. By predicting and evaluating the water environment quality after the implementation of the South-to-North Water Diversion Project, they finally reached the conclusion that water transfer would improve the water environment quality of the lake and restore the degraded ecosystem. Yang Aimin et al. (2011) ${ }^{[5]}$ used the fuzzy clustering method to analyze the ecological and environmental benefits brought by the eastern route of the South-to-North Water Transfer Project to the water demand area, and the analysis results showed that the total value of ecological and environmental benefits in the water demand area was 6.233 billion yuan, which provided a basis for the formulation of ecological and environmental protection and sustainable management strategies and measures of water resources in the Southto-North Water Transfer Project. However, due to the differences in the nature and regional characteristics of water resources development, there is no unified standard for the environmental assessment of inter-basin water transfer projects in terms of evaluation index, evaluation scope and evaluation focus.

At present, the environmental impact assessment methods for inter-basin water transfer projects mainly include matrix analysis method, BP neural network method, pollution index method, ISM method and fuzzy

*Corresponding author: ${ }^{2} 2641594770 @ q q . c o m$ 
comprehensive evaluation method, etc. Zhang Kai et al. (2020) [6] evaluated the local groundwater pollution situation by using pollution index method in groundwater pollution assessment and pollution source analysis in a certain region in southwest China, providing theoretical guidance for groundwater pollution prevention and control. Pan Liwu et al. (2012) ${ }^{[7]}$ studied the impact of the Three Gorges Project on the ecological environment in the middle and lower reaches of the Yangtze River using the Interpreted Structural Model (ISM) method, analyzed and studied the influencing factors and their relationships, and pointed out the main influencing factors of the Three Gorges Project on the ecological environment in the middle and lower reaches of the Yangtze River. He Yu et al. (2018) [8] used BP neural network model and comprehensive index evaluation method to evaluate the water quality of the main stream of Nanchong Section of Jialing River, and analyzed the main factors affecting the evolution law of water quality. However, the impact of inter-basin water transfer projects on the environment is multi-level, multi-factor and multi-stage, and its main characteristics are fuzziness and uncertainty. The single qualitative or quantitative evaluation method cannot comprehensively and systematically evaluate the environmental impact of water transfer projects, which may lead to the patchiness of evaluation results. The limitation of the pollution index method lies in the lack of analysis standards, which cannot directly and quantitatively express the degree of environmental pollution. In the multilevel hierarchical structure constructed by ISM method, there is no feedback loop between different levels, so a systematic and complete evaluation index system cannot be formed. The fuzzy comprehensive evaluation fully considers the correlation between the parameters, which is convenient for the indepth understanding of the comprehensive relationship between the parameters and corresponding standards. Therefore, this article ueses the fuzzy comprehensive evaluation method, and combines analytic hierarchy process (AHP) and fuzzy mathematical evaluation method, quantifies the qualitative indexes, and establish a multilevel fuzzy evaluation model, for the operation of the eastern route to Dongping Lake water evaluating and analyzing the impact of the ecological environment to a certain extent, improve the accuracy of the environmental impact assessment and practical. It is expected to provide scientific basis and reference for improving the environmental impact assessment system of water transfer across basins.

\section{Multi-level fuzzy comprehensive evaluation model}

\subsection{Establishment of environmental impact assessment index system}

\subsubsection{Principles of evaluation indicators}

1) The principle of independence

2) Operational principle

The simplicity and feasibility of data collection should be considered when selecting evaluation indexes.

3) Representative principle

The characteristics and changes of the ecological environment in the study area should be accurately reflected by the indicators.

4) The principle of hierarchy

5) Combination of qualitative and quantitative principles

\subsubsection{Screening of evaluation indexes}

Referring to the evaluation indexes and methods of similar water diversion projects, and considering the environmental impact that the operation of the Eastern route project may have on Dongping Lake, this paper selects the following indexes to construct the environmental evaluation index system and reflect the characteristics of the water environment of Dongping Lake: hydrometeorological, water ecological environment, soil and ecological economic compensation, etc.

Considering the principle of expert consultation method [9] , screening method and selection of evaluation indexes, this paper evaluates the hydrometeorology through the change of water storage, water level, water transfer period, evaporation, water temperature, velocity and other indexes. The water ecological environment can be reflected through the change of water quality, the change of the number and species of aquatic animals and plants. Soil is reflected by soil salinization, swamping, changes in groundwater level and river connectivity. Fishery economic compensation, water landscape compensation and agricultural irrigation compensation are used to reflect ecological economic compensation.

\subsubsection{Establishment of evaluation index system}

Based on the principles and screening of the above evaluation indexes, the analytic hierarchy process is used to establish the evaluation index system of this paper: take the impact of the operation of the Eastern route project on the water environment of Dongping Lake as the target level index, there are 4 aspects in the criterion layer and 15 indicators in the constraint layer, as shown in Table 1. 
Table1. The evaluation index system of impact of Eastern Route of South-to-North Water Diversion Project on Water Environment of Dongping Lake

\begin{tabular}{|c|c|c|}
\hline Target level & Criterion layer & Constraint layer \\
\hline \multirow{15}{*}{$\begin{array}{c}\text { A Influence } \\
\text { of East Route } \\
\text { Project Operation } \\
\text { on Water } \\
\text { Environment of } \\
\text { Dongping Lake }\end{array}$} & \multirow{6}{*}{ B1 Hydrometeorology } & C1 Change of water storage \\
\hline & & C2 Water level \\
\hline & & C3 Water transfer period \\
\hline & & C4 Evaporation \\
\hline & & C5 Water temperature \\
\hline & & C6 Velocity \\
\hline & \multirow{3}{*}{$\begin{array}{l}\text { B2 Water ecological } \\
\text { environment }\end{array}$} & C7 Change of water quality \\
\hline & & C8 Change of the number and species of animals \\
\hline & & C9 Change of the number and species of plants \\
\hline & \multirow{3}{*}{ B3 Soil } & C10 Soil salinization, swamping \\
\hline & & C11 Changes in groundwater level \\
\hline & & C12 River connectivity \\
\hline & \multirow{3}{*}{$\begin{array}{l}\text { B4 Ecological economic } \\
\text { compensation }\end{array}$} & C13 Fishery economic compensation \\
\hline & & C14 Water landscape compensation \\
\hline & & C15 Agricultural irrigation compensation \\
\hline
\end{tabular}

\subsection{Establishment of multi-level comprehensive evaluation model}

\subsubsection{Evaluation method}

Based on the analytic hierarchy process (AHP), the fuzzy mathematics theory and the fuzziness of human judgment are used to determine the weight of evaluation indexes, so as to carry out fuzzy comprehensive evaluation. In this paper, the basic idea of analytic hierarchy process (AHP) is used to compare the relative importance of the indicators in the same level in pairwise, establish the judgment matrix of the relative weight of the indicators in each level, calculate the relative importance weight, and then use the fuzzy membership function to calculate the membership degree set of the evaluation indicators. Finally, a multi-level fuzzy comprehensive evaluation model is established by combining relative importance weight and membership degree set. The specific steps of the comprehensive evaluation method are as follows ${ }^{[10]}$ :

1)Determine the evaluation factor set

Evaluation factor set refers to the set $\mathrm{M}$ composed of factors affecting water environment ecology:

$$
M=\left\{m_{1}, m_{2}, \cdots, m_{n}\right\}
$$

In this paper, it is the water environment evaluation system of Dongping Lake in the Eastern route of Southto-North Water Diversion Project.

2) Construct judgment matrix, calculate weight and consistency test

Using 1 9 scale method to compare the indexes of the same layer in pairs, the judgment matrix group is established and the weight of the indexes is calculated. Through calculating the maximum characteristic root of matrix to get the relative weight of each index, and the consistency test of the corresponding eigenvectors was carried out. The weight vector $\mathrm{W}$ is denoted as:

$$
W=\left\{W_{1}, W_{2}, \cdots, W_{n}\right\}
$$

$$
\sum_{i=1}^{n} W_{i}=1
$$

3) Determine a review set

Comment collection is the collection of various evaluation results made by industry experts to the evaluation object. Comment sets typically include 5, 7, and 9 comment levels. In this paper, the seven-level method is used to evaluate the indicators of the water environment impact of Dongping Lake, and the set of comments is expressed as: $V=\left\{V_{1}, V_{2}, V_{3}, V_{4}, V_{5}, V_{6}, V_{7}\right\}=$ $(0.95,0.80,0.65,0.50,0.35,0.20,0.05)=($ "has a great positive impact", "has a large positive impact", "has a certain positive impact", "has no significant impact", "has a certain negative impact", "has a large negative impact", "has a large negative impact")

4) Construct membership function

(1) For quantitative index, membership function in semi-trapezoidal fuzzy distribution is used to determine its membership degree. When the index value is larger, the better, its membership function is expressed as:

$$
f=\frac{X-X_{\text {min }}}{X_{\text {max }}-X_{\text {min }}}= \begin{cases}1 & x \geq X_{\text {max }} \\ \frac{X-X_{\min }}{X_{\text {max }}-X_{\min }} X_{\min }<x<X_{\text {max }} & x \leq X_{\min }\end{cases}
$$

When the index value is as small as possible, its membership function is expressed as:

$$
f=\frac{X_{\max }-x}{X_{\max }-X_{\min }}= \begin{cases}1 & x \leq X_{\min } \\ \frac{X_{\max }-x}{X_{\text {max }}-X_{\text {min }}} & X_{\min }<x<X_{\text {max }} \\ 0 & X \geq X_{\max }\end{cases}
$$

In the formula: $f$ is the index evaluation value; $X$ is the value of evaluation index; $X_{\min }$ is the lower limit of 
the evaluation index; $x_{\max }$ is the upper limit of the evaluation index.

5) Calculate evaluation scores

(1) Calculate the membership vector

$$
F^{\prime}=F W^{\prime}
$$

In the formula: $F^{\prime}$ is the membership vector; $F$ is membership degree set; $W^{\prime}$ is the weight vector.

(2) Calculate the evaluation score

$$
S=F^{\prime} V^{T}
$$

In the formula: $S$ is the evaluation score; $V^{T}$ is a set of numeric comments.

After the corresponding score is calculated by the above formula, the impact evaluation grade is determined by comparing with the evaluation set, and the final evaluation result is obtained.

\subsubsection{Determination of the weight of the index system and the value of each index}

In this paper, the analytic hierarchy process is adopted to calculate the weight of each index. This method decomposes the complex problem into different levels composed of corresponding factors through the combination of qualitative and quantitative indicators, and calculates and compares the relative importance of each index in the same level to obtain the weight of the index. The specific steps are as follows:

1)Saaty's 9-digit scaling method is used to construct judgment matrix A. See Table 2 for the specific meaning of scaling method ${ }^{[11]}$;

2) The maximum eigenvalue $\lambda_{\max }$ and eigenvector of judgment matrix A can be obtained through calculation, and $W^{(1)}$ can be obtained after normalization of eigenvector;

3) Considering the difference between the value quantity and the fixed value when comparing different indexes, it will have an inconsistency effect on the judgment matrix. When the order of the judgment matrix $n>2$, the consistency ratio $C_{R}$ is often used to test the consistency of the judgment matrix. When $C_{R}<0.1$, the judgment matrix can be considered to have complete consistency. The formula is as follows:

$$
\begin{gathered}
C_{R}=\frac{C_{I}}{R_{I}} \\
C_{I}=\frac{\lambda_{\max }-n}{n-1}
\end{gathered}
$$

In the formula: $C_{I}$ is the consistency index; $R_{I}$ is the average random consistency index, which can be obtained by calculating the arithmetic average after more than 500 repeated calculations of the random judgment matrix. See Table 3 for the values of random matrices of

\begin{tabular}{|c|c|}
\hline Scale & Meaning \\
\hline 1 & two factors are of equal importance \\
\hline 3 & $\begin{array}{l}\text { factor } \mathrm{i} \text { is slightly more important than } \\
\text { factor } \mathrm{j}\end{array}$ \\
\hline 5 & $\begin{array}{c}\text { factor } i \text { is significantly more important } \\
\text { than factor } j\end{array}$ \\
\hline 7 & factor $\mathrm{i}$ is more important than factor $\mathrm{j}$ \\
\hline 9 & $\begin{array}{l}\text { factor } i \text { is extremely important than } \\
\text { factor } j\end{array}$ \\
\hline $\begin{array}{r}2,4 \\
6,8\end{array}$ & $\begin{array}{l}\text { The median of the two adjacent } \\
\text { judgments }\end{array}$ \\
\hline
\end{tabular}
order 3 to 12 with a sample size of 1000 .
Table2. Scaling criteria and implications of the judgment matrix

Table3. Values of $R_{I} \quad 3 \sim 12$ random matrices with sample size of 1000

\begin{tabular}{|c|c|c|c|}
\hline $\begin{array}{c}\text { The } \\
\text { matrix } \\
\text { order }\end{array}$ & $\begin{array}{c}\text { Values of } \\
R_{I}\end{array}$ & $\begin{array}{c}\text { Minimal in } \\
\text { the sample } \\
R_{I}\end{array}$ & $\begin{array}{c}\text { Maximum in } \\
\text { sample } R_{I}\end{array}$ \\
\hline 3 & 0.51 & 0.00 & 3.22 \\
\hline 4 & 0.89 & 0.00 & 2.86 \\
\hline 5 & 1.12 & 0.11 & 2.62 \\
\hline 6 & 1.25 & 0.18 & 2.60 \\
\hline 7 & 1.35 & 0.36 & 2.32 \\
\hline
\end{tabular}

\section{Impact assessment of Eastern Route Project on water environment of Dongping lake}

\subsection{Overview of the study area}

Dongping Lake, located in the central and western part of Shandong Province, is the second largest freshwater lake in Shandong Province, belonging to Dongping County, Tai' an City, Shandong Province. Dongping Lake covers a total area of 627 square kilometers, with an annual water area of 124.3 square kilometers, an average depth of 2.5 meters, and a total water storage volume of 300 million cubic meters. The average annual water temperature in Dongping Lake is $14.0^{\circ} \mathrm{C}$, and 185 days in a year the water temperature is above $15^{\circ} \mathrm{C}$. Dongping Lake consists of the flood detention area and the old lake area, the two lakes are separated by the secondary lake dike. The flood detention zone, also known as the new lake area, covers an area of 423 square kilometers in the southeast, most of which is agricultural land, and serves as a flood diversion zone to prevent the Yellow River from flooding. Old Lake area, commonly known as Dongping Lake, is located in the northeast, covering an area of 209 square kilometers and holding water all year round.

\subsection{Construction of judgment matrix, weight calculation and consistency test}

1) There is a judgment matrix in the criterion layer, as shown in Table 4. 
Table4. Evaluation Matrix and Weight of Dongping Lake Standard Layer

\begin{tabular}{|c|c|c|c|c|c|}
\hline A Indicators & B1 & $\begin{array}{c}\text { B2 Water } \\
\text { ecological } \\
\text { environment }\end{array}$ & B3 Soil & $\begin{array}{c}\text { B4 Ecological } \\
\text { economic } \\
\text { compensation }\end{array}$ & $\begin{array}{c}\text { Relative } \\
\text { weights }\end{array}$ \\
\hline $\begin{array}{c}\text { B1 } \\
\text { Hydrometeorology }\end{array}$ & 1 & $1 / 2$ & 2 & 2 & 0.262 \\
\hline $\begin{array}{c}\text { B2 Water ecological } \\
\text { environment }\end{array}$ & 2 & 1 & 3 & 3 & 0.453 \\
\hline B3 Soil & $1 / 2$ & $1 / 3$ & 1 & $1 / 2$ & 0.118 \\
\hline $\begin{array}{c}\text { B4 Ecological } \\
\text { economic } \\
\text { compensation }\end{array}$ & $1 / 2$ & $1 / 3$ & 2 & 1 & 0.167 \\
\hline
\end{tabular}

The judgment matrix of criterion layer: $\lambda_{\max }=4.071$,

2) There are 4 judgment matrices in Dongping Lake constraint layer, as shown in Tables 5 to 8 . $C_{I}=0.02$, meets the conformance requirements.

Table5. Evaluation Matrix and Weight of "Hydrometeorology" Index

\begin{tabular}{|c|c|c|c|c|c|c|c|}
\hline $\begin{array}{c}\text { Bydrometeorolo } \\
\text { gy }\end{array}$ & $\begin{array}{c}\text { C1 Change } \\
\text { of water } \\
\text { storage }\end{array}$ & $\begin{array}{c}\text { C2 Water } \\
\text { level }\end{array}$ & $\begin{array}{c}\text { C3 Water } \\
\text { transfer } \\
\text { period }\end{array}$ & $\begin{array}{c}\text { C4 } \\
\text { Evaporation }\end{array}$ & $\begin{array}{c}\text { C5 Water } \\
\text { temperature }\end{array}$ & $\begin{array}{c}\text { C6 } \\
\text { Velocity }\end{array}$ & $\begin{array}{c}\text { Relative } \\
\text { weights }\end{array}$ \\
\hline $\begin{array}{c}\text { C1 Change of } \\
\text { water storage }\end{array}$ & 1 & $1 / 2$ & 3 & 3 & 4 & 5 & 0.285 \\
\hline C2 Water level & 2 & 1 & 3 & 3 & 2 & 4 & 0.308 \\
\hline $\begin{array}{c}\text { C3 Water } \\
\text { transfer period }\end{array}$ & $1 / 3$ & $1 / 3$ & 1 & $1 / 2$ & $1 / 5$ & 1 & 0.064 \\
\hline $\begin{array}{c}\text { C4 Evaporation } \\
\text { C5 Water }\end{array}$ & $1 / 3$ & $1 / 3$ & 2 & 1 & $1 / 3$ & $1 / 2$ & 0.078 \\
\hline temperature & $1 / 4$ & $1 / 2$ & 5 & 3 & 1 & 5 & 0.195 \\
\hline \begin{tabular}{c} 
C6 Velocity \\
\hline
\end{tabular} & $1 / 5$ & $1 / 4$ & 1 & 2 & $1 / 5$ & 1 & 0.070 \\
\hline
\end{tabular}

The judgment matrix of hydrometeorological indicators: $\lambda_{\max }=6.612, C_{I}=0.122, C_{R}=0.098<0.1$, meets the conformance requirements.

Table6. Evaluation Matrix and Weight of "Water Ecological Environment" Index

\begin{tabular}{|c|c|c|c|c|}
\hline $\begin{array}{c}\text { B2 Water ecological } \\
\text { environment }\end{array}$ & $\begin{array}{c}\text { C7 Change of } \\
\text { water quality }\end{array}$ & $\begin{array}{c}\text { C8 Change of the } \\
\text { number and species } \\
\text { of animals }\end{array}$ & $\begin{array}{c}\text { C9 Change of the } \\
\text { number and species of } \\
\text { plants }\end{array}$ & $\begin{array}{c}\text { Relative } \\
\text { weights }\end{array}$ \\
\hline $\begin{array}{c}\text { C7 Change of water } \\
\text { quality }\end{array}$ & 1 & 3 & 2 & 0.550 \\
\hline $\begin{array}{c}\text { C8 Change of the } \\
\text { number and species } \\
\text { of animals }\end{array}$ & $1 / 3$ & 1 & 1 & 0.210 \\
\hline $\begin{array}{c}\text { C9 Change of the } \\
\text { number and species } \\
\text { of plants }\end{array}$ & $1 / 2$ & 1 & 1 & 0.240 \\
\hline
\end{tabular}

The judgment matrix of Water ecological environment index : $\lambda_{\max }=3.018, C_{I}=0.009, C_{R}=0.018<0.1$, meets the conformance requirements. 
Table7. Evaluation Matrix and Weight of "Soil and Other" Index

\begin{tabular}{|c|c|c|c|c|}
\hline B3 Soil & $\begin{array}{c}\text { C10 Soil salinization, } \\
\text { swamping }\end{array}$ & $\begin{array}{c}\text { C11 Changes in } \\
\text { groundwater level }\end{array}$ & $\begin{array}{c}\text { C12 River } \\
\text { connectivity }\end{array}$ & $\begin{array}{c}\text { Relative } \\
\text { weights }\end{array}$ \\
\hline $\begin{array}{c}\text { C10 Soil salinization, } \\
\text { swamping }\end{array}$ & 1 & $1 / 2$ & 3 & 0.332 \\
\hline $\begin{array}{c}\text { C11 Changes in } \\
\text { groundwater level }\end{array}$ & 2 & 1 & 3 & 0.528 \\
\hline C12 River connectivity & $1 / 3$ & $1 / 3$ & 1 & 0.140 \\
\hline
\end{tabular}

The judgment matrix of soil index: $\lambda_{\max }=3.054, C_{I}$ $=0.027, C_{R}=0.052<0.1$, meets the conformance requirements.

Table8. Evaluation Matrix and Weight of "Ecological Economy Compensation" Index

\begin{tabular}{|c|c|c|c|c|}
\hline $\begin{array}{c}\text { B4 Ecological } \\
\text { economic } \\
\text { compensation }\end{array}$ & $\begin{array}{c}\text { C13 Fishery } \\
\text { economic } \\
\text { compensation }\end{array}$ & $\begin{array}{c}\text { C14 Water landscape } \\
\text { compensation }\end{array}$ & $\begin{array}{c}\text { C15 Agricultural } \\
\text { irrigation compensation }\end{array}$ & $\begin{array}{c}\text { Relative } \\
\text { weights }\end{array}$ \\
\hline $\begin{array}{c}\text { C13 Fishery } \\
\text { economic } \\
\text { compensation }\end{array}$ & 1 & 3 & 2 & 0.550 \\
\hline $\begin{array}{c}\text { C14 Water } \\
\text { landscape } \\
\text { compensation }\end{array}$ & $1 / 3$ & 1 & 1 & 0.210 \\
\hline $\begin{array}{c}\text { C15 } \\
\text { Agricultural } \\
\text { irrigation } \\
\text { compensation }\end{array}$ & $1 / 2$ & 1 & 1 & 0.240 \\
\hline
\end{tabular}

The judgment matrix of ecological and economic compensation index: $\lambda_{\max }=3.018, C_{I}=0.009, C_{R}$ $=0.018<0.1$, meets the conformance requirements.
The membership degree of each indicator is obtained through the calculation of membership function, and the membership degree set of environmental impact assessment indicators is established, as shown in Table 9.

\subsection{Establish index membership set}

Table9. Membership set of evaluation indicators

\begin{tabular}{|c|c|c|}
\hline Criterion layer & Constraint layer & Membership set \\
\hline \multirow{6}{*}{$\begin{array}{c}\text { B1 } \\
\text { Hydrometeorology }\end{array}$} & C1 Change of water storage & $(0,0.7,0.3,0,0,0,0)$ \\
\hline & C2 Water level & $(0,0,0,0.5,0.5,0,0)$ \\
\hline & C3 Water transfer period & $(0,0,0,0,1,0,0)$ \\
\hline & C4 Evaporation & $(0,0,0,1,0,0,0)$ \\
\hline & C5 Water temperature & $(0,0,0,0,0.4,0.6,0)$ \\
\hline & C6 Velocity & $(0,0,0,0,1,0,0)$ \\
\hline \multirow{3}{*}{$\begin{array}{c}\text { B2 Water } \\
\text { ecological } \\
\text { environment }\end{array}$} & C7 Change of water quality & $(0,0,0,1,0,0,0)$ \\
\hline & C8 Change of the number and species of animals & $(0,0,0.8,0.2,0,0,0)$ \\
\hline & C9 Change of the number and species of plants & $(0,0,0,0.6,0.4,0,0)$ \\
\hline \multirow{3}{*}{ B3 Soil } & C10 Soil salinization, swamping & $(0,0,0,0,0,1,0)$ \\
\hline & C11 Changes in groundwater level & $(0,0,0,0,0.5,0.5,0)$ \\
\hline & C12 River connectivity & $(0,0,0,0.5,0.5,0,0)$ \\
\hline \multirow{3}{*}{$\begin{array}{l}\text { B4 Ecological } \\
\text { economic } \\
\text { compensation }\end{array}$} & C13 Fishery economic compensation & $(0,0,0,1,0,0,0)$ \\
\hline & C14 Water landscape compensation & $(0,0,0,0.4,0.6,0,0)$ \\
\hline & C15 Agricultural irrigation compensation & $(0,0,0,0,1,0,0)$ \\
\hline
\end{tabular}




\subsection{Comprehensive assessment of water environmental impact}

1) According to Table 5, the index weight vector of "hydrometeorology" in Dongping Lake is:

$$
W_{B 1}^{\prime}=(0.285,0.308,0.064,0.078,0.195,0.070)
$$

The corresponding membership degree set is:

$$
F_{B 1}^{\prime}=\left|\begin{array}{ccccccc}
1 & 0 & 0 & 0 & 0 & 0 & 0 \\
0 & 0.5 & 0.5 & 0 & 0 & 0 & 0 \\
0 & 0 & 0 & 0 & 1 & 0 & 0 \\
0 & 0 & 0 & 1 & 0 & 0 & 0 \\
0 & 0 & 0 & 0 & 0.4 & 0.6 & 0 \\
0 & 0 & 0 & 1 & 0 & 0 & 0
\end{array}\right|
$$
is:

Then, the membership vector of "hydrometeorology"

$$
F_{B 1}{ }^{\prime}=W_{B 1}{ }^{\prime} F_{B 1}=
$$

$(0,0.20,0.085,0.232,0.366,0.117,0)$

The relative evaluation score is:

$$
S_{B 1}=F_{B 1}{ }^{\prime} V^{T}=0.483
$$

In the range of $0.05-0.95$, the higher the value of hydrometeorological evaluation, the better. According to the numerical evaluation set, it can be concluded that the operation of the eastern route of South-to-North Water Transfer Project will have a small negative impact on the hydrometeorological of Dongping Lake, which is mainly reflected in the deviation of the change of water storage amount from the suitable water storage amount of Dongping Lake after water transfer.

2) In the same way, the membership vector and relative evaluation score of "water ecological environment" can be calculated as follows:

$$
\begin{gathered}
F_{B 2}{ }^{\prime}=W_{B 2}{ }^{\prime} F_{B 2}=(0,0,0.168,0.736,0.096,0,0) \\
S_{B 2}=F_{B 2}{ }^{\prime} V^{T}=0.511
\end{gathered}
$$

In the range of $0.05-0.95$, the higher the evaluation value of this criterion layer, the better. It can be seen that the operation of the eastern route project has no obvious impact on the water ecology of Dongping Lake.

3) The "soil" membership vector and relative evaluation score can be calculated as follows:

$$
\begin{gathered}
F_{B 3}{ }^{\prime}=W_{B 3}{ }^{\prime} V^{T}=(0,0,0,0.07,0.334,0.596,0) \\
S_{B 3}=F_{B 3}{ }^{\prime} V^{T}=0.271
\end{gathered}
$$

According to the evaluation, the soil and other aspects of Dongping Lake have been affected negatively after the operation of the eastern route of the South-to-North Water Transfer Project, which is mainly reflected in the intensification of salinization and swamping and the decline of river connectivity after the diversion.

4) Similarly, the membership vector of "ecological and economic compensation" and the relative evaluation score are:

$$
\begin{gathered}
F_{B 4}{ }^{\prime}=W_{B 4}{ }^{\prime} F_{B 4}=(0,0,0,0.634,0.366,0,0) \\
S_{B 4}=F_{B 4}{ }^{\prime} V^{T}=0.445
\end{gathered}
$$

It can be seen that the eastern route project has a negative impact on the ecological and economic compensation of Dongping Lake, mainly because of the insufficient compensation of fishery economy and agricultural irrigation.

5) From the above calculation results, membership degree set of the criterion layer relative to the target layer can be obtained as follows:

$$
F_{A}^{T}=\left|\begin{array}{cccc}
0.285 & 0.550 & 0 & 0 \\
0.154 & 0.168 & 0 & 0 \\
0.154 & 0.042 & 0 & 0 \\
0.148 & 0.144 & 0.070 & 0.634 \\
0.142 & 0.096 & 0.334 & 0.366 \\
0.117 & 0 & 0.596 & 0 \\
0 & 0 & 0 & 0
\end{array}\right|
$$

According to Table 4, the weight vector of the criterion layer relative to the target layer is:

$$
W_{A}^{\prime}=(0.262,0.453,0.118,0.167)
$$

Calculate the membership vector of the target layer:

$$
F_{A}^{\prime}=W_{A}^{\prime} F_{A}=(0,0.052,0.099,0.508,0.241,0.101,0)
$$

The final evaluation score is:

$$
S_{A}=F_{A}^{\prime} V^{T}=0.464
$$

The final score of the water environmental impact assessment of Dongping Lake is 0.464 . The score shows that the operation of the eastern route project has brought some negative effects on Dongping Lake, especially on soil, followed by ecological and economic compensation. The negative effects on hydrology and meteorology are small, and the impact on the water ecological environment is not obvious.

\section{Conclusions}

Based on the analysis and study of the influence of the Eastern route project on the water environment of Dongping Lake, this paper establishes the evaluation index system of the impact of the water diversion project on the water ecological environment, and constructs the multi-level fuzzy evaluation model. A quantitative and qualitative study is made on the impacts of hydrology, meteorology, water ecological environment, soil and other aspects as well as ecological and economic compensation, etc. Scientific evaluation is made on the effects of the operation of the Eastern route of the South-to-North Water Diversion Project on Dongping Lake, and the following conclusions are drawn:

1) The increase of water storage leads to the increase of water level and the change of velocity of Dongping Lake, which leads to the change of hydrology and meteorology of Dongping Lake. At the same time, the increase of water level has brought great challenges to the 
lake dam. Water leakage and other phenomena appear in the flood season, which poses a threat to the safety of the surrounding residents and the land.

2) The water level of Dongping Lake is maintained at $41.5 \mathrm{~m}$ all the year round, but in the water transfer period, the water level will rise by $1.2 \mathrm{~m}$, which will cause a large range of immersion to the surrounding land, especially the south dam section, resulting in the salinization of the land. At the same time, there are leakage problems in the secondary dike of Dongping Lake, which has a great influence on the submersion outside the dike.

3) During the construction of the eastern route, in order to ensure that the water quality of Dongping Lake reaches the standard, it is necessary to clean up the reservoir for migration and fishery, which will greatly affect the production and life of the fishermen in the original lake. The smooth withdrawal of fishing, the transfer of production and the livelihood guarantee of lake fishermen play a key role in the orderly development and operation of the water diversion project.

4) There are many water qualities risks during the water transfer process of the eastern route of the South-toNorth Water Diversion Project, which may lead to water quality problems in Dongping Lake, the last storage lake of the eastern route project, and further affect the survival and reproduction of aquatic organisms in Dongping Lake, leading to the deterioration of the water environment.

Therefore, the ecological civilization concept of "respecting nature, conforming to nature and protecting nature" must be established during the construction and operation of the inter-basin water transfer project, and the environmental impact assessment of the water transfer project must be strengthened, and the project scheme adapting to the water environment must be continuously optimized. Based on the conclusions of the impact assessment of the eastern route project on the water environment of Dongping Lake, this paper puts forward the following targeted suggestions:

1) Scientific formulation of water storage and water level of Dongping Lake

When determining the water storage capacity and water level of Dongping Lake, the actual water storage capacity of the reservoir should be fully considered, and the embankment and flood control works of Dongping Lake should be reinforced and renovated to ensure that they can meet the flood control standard. At the same time, in order to enlarge the water storage capacity of the old lake, the production embankment should be abolished and the farmland should be returned to the lake, so as to avoid the danger caused by excessive water storage and highwater level during the water transfer cycle.

2) Establish a professional organization to strengthen the water quality supervision and management of Dongping Lake

Dongping Lake, as an important regulating and storing lake and water transmission channel of the Eastern Route of South-to-North Water Diversion Project, shoulders important responsibilities of water storage, flood control, water diversion, water supply, irrigation, etc., so it is of great significance to ensure its water quality. Therefore, it is necessary to set up a professional water quality supervision organization, strengthen the comprehensive management of the lake, reduce and control the pollution sources of the lake, ensure the ecological security and water quality of Dongping Lake to meet the standards, and make it play a greater role in the water diversion project.

3) Firmly implement the compensation support policy

Whether the compensation and support policies for fishermen and migrants in Dongping Lake are in place is related to the smooth implementation and operation of the eastern route of the South-to-North Water Diversion Project. Therefore, it is necessary to increase the financial compensation to the lake fishermen in the early period of withdrawal from fishing and the policy and employment support in the later period of production conversion, properly settle the production and life of the lake fishermen and migrants, and ensure the stability of their income sources after withdrawal from fishing and production conversion.

\section{References}

1. Pang Jingpeng. Journal of Natural Science of Harbin Normal University,2003(06):96-99.

2. Xin Xu, Zhaohui Ni, Ziwei Shen, Nan Wang, Boqun Liu. Study on the influence of water transfer project on ecological environment in water source area $[\mathrm{J}]$. Ecological Economics,2018,34(07):174-178.

3. Guo Hua, Xiao Weihua, Shang Jingshi, Wang Wenchuan. Impact assessment on water environment of Nansi Lake during the operation of the eastern route of South-to-North Water Transfer Project [J]. South-to-North Water Transfer and Water Science and Technology,2013,11(06):49-53+57.

4. Luo Hui, Zhou Jianren, Guo Zhong. Journal of Hohai University (Natural Science Edition),2005(01):63-67.

5. Aimin Yang, Lu Zhang, Hong Gan, Hao Wang. Ecological and environmental benefit assessment of the water receiving area of the first phase of the eastern route of the South-to-North Water Transfer Project $[\mathrm{J}]$. Journal of Hydraulic Engineering,2011,42(05):563-571.

6. Zhang Kai, Zheng Xinhui, Li Xiaonan, Li Jinhua, Ji Yuning, Gao Hao. Journal of Henan Normal University (Natural Science Edition),2020,48(05):6473.

7. Liwu Pan, Jianzhong Zhou, Xingwen Jiang, Yuhong Li. Impact of the Three Gorges Project on the ecological environment in the middle and lower reaches of the Yangtze River [J]. Hydropower and Energy Science,2012,30(04):97-99+201.

8. He Yu, Tang Ying, Chen Lanying, Li Yunxiang, Jing Anbing, Xiao Juan. Environmental Protection Science, 2018,44(03):114-120+126.

9. Guo Xiao, Fang Guohua, Zhang Zhekai. Journal of Hydraulic Engineering,2008(09):1125-1130+1135.

10. Lan Shengtao, Zhou Hong, Zeng Yuanmeng, Zhu Wenting, Qi Lingxuan. Evaluation of strata water content in karst area based on fuzzy comprehensive evaluation method: A case study of Cambrian strata in 
Three Gorges area [J]. Safety and Environmental Engineering, 201,28(02):133-141.

11. Ma Hongjuan, Shi Xizhuan, Liu Wanli. Research on fuzzy comprehensive evaluation of water environment based on entropy weight method and multi-level analysis method [J]. Mathematics in Practice and Theory,2015,45(06):154-164 